\title{
Complexity Analysis of a Triopoly Cooperation-Competition Game Model in Convergence Product Market
}

\author{
Liming Zhao, Xiaofeng Liu, and Ning Ji \\ College of Management and Economics, Tianjin University, Tianjin 300072, China \\ Correspondence should be addressed to Ning Ji; ningji@tju.edu.cn
}

Received 30 September 2016; Accepted 19 December 2016; Published 15 January 2017

Academic Editor: Eric Campos-Canton

Copyright (C) 2017 Liming Zhao et al. This is an open access article distributed under the Creative Commons Attribution License, which permits unrestricted use, distribution, and reproduction in any medium, provided the original work is properly cited.

\begin{abstract}
This work considered a tripartite cooperation-competition game model for the convergence product market, whose products are compounds of two base products or services. An early convergence product firm monopoly in this market and two potential entrants from the base products decide to cooperate with another to compete with the monopolist. We analyzed factors that affect existence and local stability of the Nash equilibrium. Rich nonlinear dynamic behaviors like bifurcation, chaos, and attractors are presented to explain the complex relationships between the three players. Results showed that the pulling effect on profit for the united $\mathrm{R} \& \mathrm{D}$ activity can significantly enlarge the stable region. Too frequently adjusted price strategy will bring the system into chaos. A parameter feedback control method is given to control the chaotic system and we numerically verified its effectiveness. This study has significant values to understand the fluctuations in related convergence product market.
\end{abstract}

\section{Introduction}

Convergence is a dominant paradigm in the contemporary industry innovation, which allows the introduction of seemingly disparate attributes or functionalities products into other existing industrial categorized products. As in China, the flourishing "Internet Plus" strategy, which means the conventional industries adopt the application of the Internet and other information technologies to reform the existing mode of products, is regarded as an important way to produce its new economic form and promote emerging industry [1].

For abbreviations, the base products are called BPs and the newly formed convergence products are called CPs. In a newly built CPs market, relying on its information, differentiation characteristics, and prior advantages over the competitors, an early entry firm is easy to monopoly the whole market [2]. With the fast growing CPs industry, owing to the similar product type and alternative functionalities, firms in BPs industry are the most probable potential entrants to compete with the monopolist, separately [3], while, in the context of CPs, because of the product segment in CPs industry which brings entry barrier for potential entrants, firms in BPs tend to complement and upgrade its product line to take a share in the rising CPs $[4,5]$. The competitive structure and cooperative trend in CPs market will be changed.

Many researchers have contributed incremental values to extend the classical Cournot game and Bertrand game into different forms with practical variations in real economy $[6,7]$. In [8], researchers built a duopoly game model for two zonal electricity firms which is an administrative monopolist granted by the bureaucracy in separate market and investigated its complex dynamics. Chen et al. [9] proposed a dynamic triopoly game model in Chinese $3 \mathrm{G}$ telecommunication market, which is a typical natural monopolized market. For the published literature, researchers interest on monopoly game has transformed from duopoly game $[7,10$, $11]$ to triopoly game $[8,12,13]$. And the basic assumption has been modified from complete rational to bounded rational $[13,14]$. In [15], the existence of chaotic dynamics for a triopoly game model with different decisional mechanism was rigorously proved by the "Stretching along the Paths (SAP)" method. However, for the third types of monopoly, the economic monopoly, which means firms acquire the monopoly status relying on powerful economic strength, 
enormous paten ownership, and successful marketing strategy, is always regarded as the product of free completion and progress in science and technology. Under the background of economic globalization, the economic monopoly seems more acceptable by enhancing the competitiveness of a country, but it is also unsupported by government if it has touched fairness of the market. For instance, the US government has repeatedly inquired Microsoft on its monopoly and tying conduct [16].

In the process of industry convergence, the compounding characteristics of CPs and strong user stickiness can considerably cause monopoly in this market. On the one hand, convergence has accelerated the pace of breaking up boundaries and disintegrating of monopolists in existing industry [17]. On the other hand, by adding new functionalities to existing product to realize complementary goals, firms in CPs market achieved powerful marketing and sales benefits. For example, iPhones have helped Apple Inc. in monopolizing most of the profits in high-end smart phone industry, which is a revolutionary convergence in telecommunication and other Internet services [18]. Because of the natural strengths in transforming single products by introducing the complementary attributes and lack of experiences in the opposite field, firms in BPs will be guided to cooperate with its complementary firms to exploit in CPs. Thus, if the two united firms successfully fulfill their product transformation, the complex cooperation and competition behaviors among the three firms can form a triopoly cooperation-competition game in CPs market.

In this paper, we develop the complexity of convergence theory to build a three-dimensional discrete cooperationcompetition game model in CPs market. A price adjustment dynamic strategy is used to investigate the complex dynamic features of this model and the stability of the Nash equilibrium. Our result aims to show the influence of the cooperation-competition behaviors on CPs market and find out proper strategies to control chaos when this system enters into chaos state.

The rest of this paper is organized as follows: In Section 2, we describe the triopoly cooperation-competition game model with bounded rationality. In Section 3, we discuss the existence and local stability of the Nash equilibrium. In Section 4, the numerical simulations of the dynamical behaviors for this model are investigated. Finally, conclusions are given in Section 5 .

\section{The Triopoly Cooperation-Competition Game Model}

We consider two potential entrants from the basic markets (denoted by firm 1 and firm 2), who consist of the two aspects of the compounding attributes for CPs, and an early entry firm in CPs market (denoted by firm 3). Having seeing the fast rising of excess profits in CPs market and similar product structure, the two firms from BPs decided to cooperate with each other to research and develop new CPs in continuous periods by adding the complementary functionality into its existing products. The expenditure of research and development $(\mathrm{R} \& \mathrm{D})$ will prorate between the two united firms and the proportion depends on the preexisting R\&D ability and the effort level in the cooperation process. For firm 3, on the one hand, the excellent characteristics of CPs and the accumulative experience in CPs market provide it with a huge amount of demand and a relatively low cost. On the other hand, the newly launched products from the two cooperative firms bring a rise in publicity and an overall sales improvement for CPs. For the sake of risk aversion in R\&D, firm 3 decides to hold its product line unchanged and expects to get a free ride of rise in demand. Thus, the new products of firms 1 and firm 2 will gradually form a substitution for products of firm 3 in CPs.

Let $q_{i}(t)$ denote the output of products by firm $i$ at period $t$ and $p_{i}(t)$ denote the corresponding prices $(i=1,2,3)$. Since the product of each firm has complementary attributes in CPs market, according to [10], the demand function of the three firms can be given as

$$
\begin{aligned}
& q_{1}(t)=a_{1}-b_{1} p_{1}(t)+c_{1} p_{2}(t)+d_{1} p_{3}(t), \\
& q_{2}(t)=a_{2}-b_{2} p_{2}(t)+c_{2} p_{1}(t)+d_{2} p_{3}(t), \\
& q_{3}(t)=a_{3}-b_{3} p_{3}(t)+c_{3} p_{1}(t)+d_{3} p_{2}(t),
\end{aligned}
$$

where $a_{i}$ is the maximum demand in the market, $b_{i}$ is the price elasticity of demand $q_{i}(t)$ regarding on product $i$, and $c_{i}$ and $d_{i}$ are the cross-price elasticity of demand $q_{i}(t)$ regarding on the complementary product $j$ and product $k(j, k=1,2,3$, $j, k \neq i$, and $j \neq k)$. All the parameters above are positive and satisfy the restrict conditions of $0<b_{i}, c_{i}, d_{i} \leq 1, b_{i}>c_{i}$, and $b_{i}>d_{i}$; that is, the ownership price effect is greater than the complementary cross-price effect.

The innovative activities to develop new CPs will raise the cost of firm 1 and firm 2 . We suppose that the R\&D cost for the cooperative union is a linear function of the production. It can be given as

$$
E=(e-r)\left(q_{1}+q_{2}\right)
$$

where $e-r$ represents the marginal cost of $\mathrm{R} \& \mathrm{D}, e$ represents the present marginal R\&D cost, and $r$ represents the effort level in collaborative R\&D activity. The R\&D cost is proportional to the total output. It means that the innovation activity becomes more difficult in a larger scale of production. Considering the intrinsic fixed cost and variable cost of firm 1 and firm 2, the total cost function can be written as

$$
\begin{aligned}
C_{1} & =f_{1}+g_{1} q_{1}+\theta E=f_{1}+g_{1} q_{1}+\theta(e-r)\left(q_{1}+q_{2}\right), \\
C_{2} & =f_{2}+g_{2} q_{2}+(1-\theta) E \\
& =f_{2}+g_{2} q_{2}+(1-\theta)(e-r)\left(q_{1}+q_{2}\right),
\end{aligned}
$$

where $f_{1}$ and $f_{2}$ are the fixed costs, $g_{1}$ and $g_{2}$ are coefficients of the variable costs, and $\theta$ and $1-\theta$ denote the proportion of the $\mathrm{R} \& \mathrm{D}$ cost between the union.

With the above assumption, the cost function of firm 3 is given by

$$
C_{3}=f_{3}+g_{3} q_{3},
$$

where $f_{3}<f_{1}$ and $f_{3}<f_{2}$, which denote the cost advantage for the early entry firm. 
Let $\lambda$ denote the pulling effect on profit for the united $\mathrm{R} \& \mathrm{D}$ activity of firm 1 and firm 2. $I_{i}$ is the indicator function that takes value 1 for $i=1,2$ and takes value 0 for $i=3$. Then we can get the profit function of firm $i$ at period $t$ :

$$
\pi_{i}(t)=p_{i}(t)\left(1+\lambda I_{i}\right) q_{i}-C_{i}, \quad i=1,2,3 .
$$

We assume that this is an incomplete information market. All of the three firms choose the bounded rational adjustment strategy based on the marginal profit in the next period:

$$
\begin{aligned}
& p_{1}(t+1)=p_{1}(t)+\alpha p_{1}(t) \frac{\partial \pi_{1}(t)}{\partial p_{1}(t)}, \\
& p_{2}(t+1)=p_{2}(t)+\beta p_{2}(t) \frac{\partial \pi_{2}(t)}{\partial p_{2}(t)} \\
& p_{3}(t+1)=p_{3}(t)+\gamma p_{3}(t) \frac{\partial \pi_{3}(t)}{\partial p_{3}(t)}
\end{aligned}
$$

where $\alpha>0, \beta>0$, and $\gamma>0$ are the adjustment speed for the three firms, respectively. By substituting (5) into (6), we obtain the dynamic model of a triopoly cooperationcompetition game model in the convergence product market:

$$
\begin{aligned}
& p_{1}(t+1)=p_{1}(t)+\alpha p_{1}(t) \\
& \quad \times\left[(1+\lambda)\left(a_{1}-b_{1} p_{1}(t)+c_{1} p_{2}(t)+d_{1} p_{3}(t)\right)\right. \\
& \left.\quad-b_{1}(1+\lambda) p_{1}(t)-(e-r)\left(c_{2}-b_{1}\right) \theta+b_{1} g_{1}\right], \\
& p_{2}(t+1)=p_{2}(t)+\beta p_{2}(t) \\
& \quad \times\left[(1+\lambda)\left(a_{2}-b_{2} p_{2}(t)+c_{2} p_{1}(t)+d_{2} p_{3}(t)\right)\right. \\
& \left.\quad-b_{2}(1+\lambda) p_{2}(t)-(e-r)\left(c_{1}-b_{2}\right)(1-\theta)+b_{2} g_{2}\right], \\
& p_{3}(t+1)=p_{3}(t)+\gamma p_{3}(t)\left[a_{3}+b_{3} g_{3}+c_{3} p_{1}+d_{3} p_{2}\right. \\
& \left.\quad-2 b_{3} p_{3}\right] .
\end{aligned}
$$

\section{The Complex Dynamic Behaviors}

3.1. The Nash Equilibrium and Stability Analysis. In system (7), we can get that this discrete system has eight equilibrium points with forms of $(0,0,0),\left(p_{1}^{1}, 0,0\right),\left(0, p_{2}^{1}, 0\right),\left(0,0, p_{3}^{1}\right)$, $\left(0, p_{2}^{2}, p_{3}^{2}\right),\left(p_{1}^{2}, 0, p_{3}^{2}\right),\left(p_{1}^{2}, p_{2}^{2}, 0\right)$, and $\left(p_{1}^{*}, p_{2}^{*}, p_{3}^{*}\right)$. The three firms in the game will not supply any production to the market at price 0 .

Hence, the nontrivial equilibrium point $\left(p_{1}^{*}, p_{2}^{*}, p_{3}^{*}\right)$ is the only Nash equilibrium with positive component values. It can be found that values of the nontrivial equilibrium point are parameter dependent in system (7) except for $\alpha, \beta$, and $\gamma$. For denotations, we numerically give out values in Section 3.2.

In order to study the stability of the system at $\left(p_{1}^{*}, p_{2}^{*}, p_{3}^{*}\right)$, the Jacobian matrix of (7) can be given as

$$
J\left(p_{1}^{*}, p_{2}^{*}, p_{3}^{*}\right)=\left[\begin{array}{lll}
j_{11} & j_{12} & j_{13} \\
j_{21} & j_{22} & j_{23} \\
j_{31} & j_{32} & j_{33}
\end{array}\right],
$$

where

$$
\begin{aligned}
\Delta_{1} & =\alpha\left[(1+\lambda)\left(a_{1}-b_{1} p_{1}^{*}+c_{1} p_{2}^{*}+d_{1} p_{3}^{*}\right)\right. \\
& \left.-b_{1}(1+\lambda) p_{1}^{*}-(e-r)\left(c_{2}-b_{1}\right) \theta+b_{1} g_{1}\right] \\
& -2 \alpha b_{1}(1+\lambda) p_{1}^{*}, \\
\Delta_{2} & =\beta\left[(1+\lambda)\left(a_{2}-b_{2} p_{2}^{*}+c_{2} p_{1}^{*}+d_{2} p_{3}^{*}\right)\right. \\
& \left.-b_{2}(1+\lambda) p_{2}^{*}-(e-r)\left(c_{1}-b_{2}\right)(1-\theta)+b_{2} g_{2}\right] \\
& -2 \beta b_{2}(1+\lambda) p_{2}^{*}, \\
\Delta_{3} & =\gamma\left[a_{3}+b_{3} g_{3}+c_{3} p_{1}^{*}+d_{3} p_{2}^{*}-2 b_{3} p_{3}^{*}\right]-2 \gamma b_{3} p_{3}^{*} ; \\
j_{11} & =1+\Delta_{1}, \\
j_{12} & =\alpha c_{1}(1+\lambda) p_{1}^{*}, \\
j_{13} & =\alpha d_{1}(1+\lambda) p_{1}^{*} ; \\
j_{21} & =\beta c_{2}(1+\lambda) p_{2}^{*}, \\
j_{22} & =1+\Delta_{2}, \\
j_{23} & =\beta d_{2}(1+\lambda) p_{2}^{*} ; \\
j_{31} & =\gamma c_{3} p_{3}^{*}, \\
j_{32} & =\gamma d_{3} p_{3}^{*}, \\
j_{33} & =1+\Delta_{3} .
\end{aligned}
$$

Hence, the characteristic equation of system (7) at $\left(p_{1}^{*}, p_{2}^{*}, p_{3}^{*}\right)$ is given by

$$
f(\lambda)=\lambda^{3}+A \lambda^{2}+B \lambda+C,
$$

where $A=-\left(j_{11}+j_{22}+j_{33}\right), B=-\left(-j_{11} j_{22}-j_{11} j_{33}+j_{21}^{2}-\right.$ $\left.j_{22} j_{33}+j_{23} j_{32}+j_{31}^{2}\right)$, and $C=-j_{11} j_{22} j_{33}+j_{11} j_{23} j_{32}+j_{21}^{2} j_{33}-$ $j_{21} j_{23} j_{31}-j_{21} j_{31} j_{32}+j_{22} j_{31}^{2}$.

According to the Jury conditions in [19], the Nash equilibrium $\left(p_{1}^{*}, p_{2}^{*}, p_{3}^{*}\right)$ of system (7) is locally stable if and only if the following conditions hold:

$$
\begin{aligned}
& f_{1}=A+B+C+1>0, \\
& f_{2}=A-B+C-1<0, \\
& f_{3}=1-C^{2}>0, \\
& f_{4}=\left(1-C^{2}\right)^{2}-(B-A C)^{2}>0 .
\end{aligned}
$$

In this case, prices in the CPs market will reach the Nash equilibrium after limited rounds of games with random initial values. The Nash point is stable in the region consisting of the adjusted speed parametric space $(\alpha, \beta, \gamma)$.

3.2. Numerical Simulations. In this triopoly game, the three firms choose the optimal price strategy to maximize their profits in the CPs market and adjust the price according to the marginal profit in the next period. While changes of the 


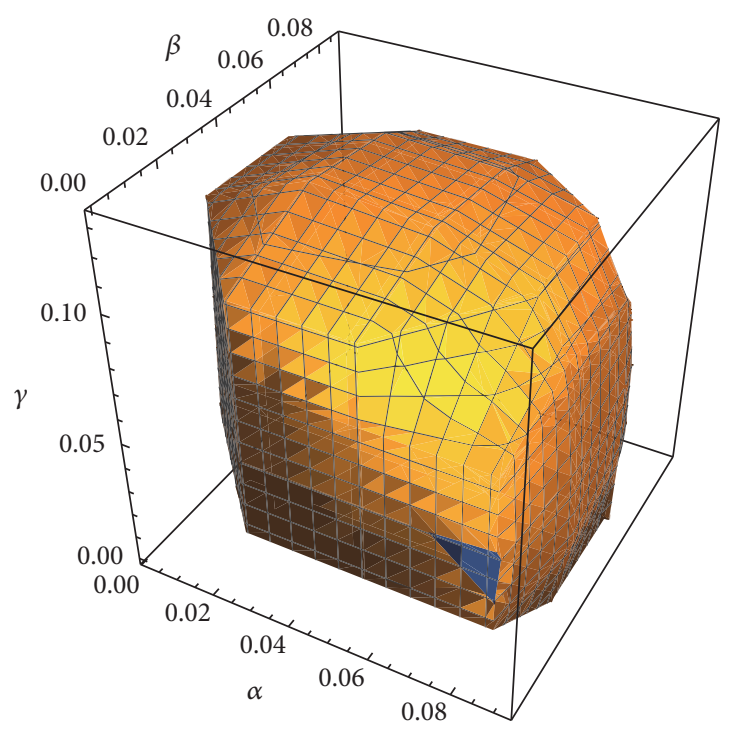

(a) The stable region with $\lambda=0.2$

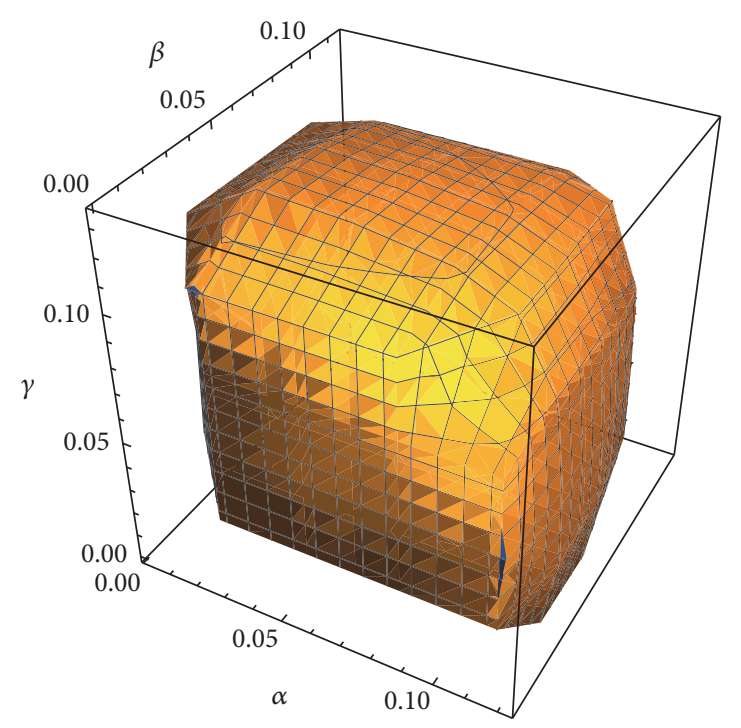

(b) The stable region with $\lambda=0.8$

FIGURE 1: The stable region of the equilibrium with different values of the pulling effect.

adjustment speed $\alpha, \beta$, and $\gamma$ will not influence the values of the Nash equilibrium, we discuss the complex dynamic behaviors of these parameters.

Given a group of parameters $a_{1}=a_{2}=6.5, a_{3}=8.25, b_{1}=$ $b_{2}=b_{3}=1, c_{1}=c_{2}=0.30, c_{3}=d_{1}=0.35, d_{2}=d_{3}=0.40$, $f_{1}=f_{2}=6.50, f_{3}=6, g_{1}=g_{2}=2, g_{3}=1.40, e=0.75, r=$ $0.46, \lambda=0.8$, and $\theta=0.5$. The positive solutions of system (7) are $p_{1}^{*}=6.00, p_{2}^{*}=6.16$, and $p_{3}^{*}=7.11$. In the above analysis, we know that different values of $\lambda$ can affect the stability of the triopoly cooperation-competition game (7).

As shown in Figure 1, it is noted that the stable region surrounded by the yellow volume is irregular and asymmetric for approximate critical values of $\alpha<0.08, \beta<0.08$, and $\gamma<0.11$. The stable region is larger for $\lambda=0.8$ than that of $\lambda=0.2$, which means that larger pulling effect on profit for the united $\mathrm{R} \& \mathrm{D}$ activity is conductive to enlarge the stable region of the CPs market.

For given values of $\beta=0.075$ and $\gamma=0.08$, Figure 2 shows the price bifurcation diagram of the three firms by taking the adjustment speed $\alpha$ as bifurcating parameter. According to definitions of Lyapunov exponent given in [20], Figure 3 shows the corresponding diagram of the largest Lyapunov exponent. We can see that, for $\alpha<0.08342$, the Nash equilibrium is locally stable and the largest Lyapunov exponents are negative. The system generates the first flip bifurcation at $\alpha=0.08342$. With the increase of $\alpha$, the system turns to be more complicated. When $\alpha>0.1151$, system (7) has a positive largest Lyapunov exponent, which indicates that the system has entered into chaos state. It means that if the firm 1 from BPs market makes excessive adjustment to adapt itself in the CPs market, this market will gradually become unpredictable and uncontrollable.

The strange attractor is another characteristic of a chaotic system. As shown in Figure 4 when $\beta=0.075, \gamma=0.08$, and $\alpha=0.1233$, the system is in chaos and exhibits a fractal

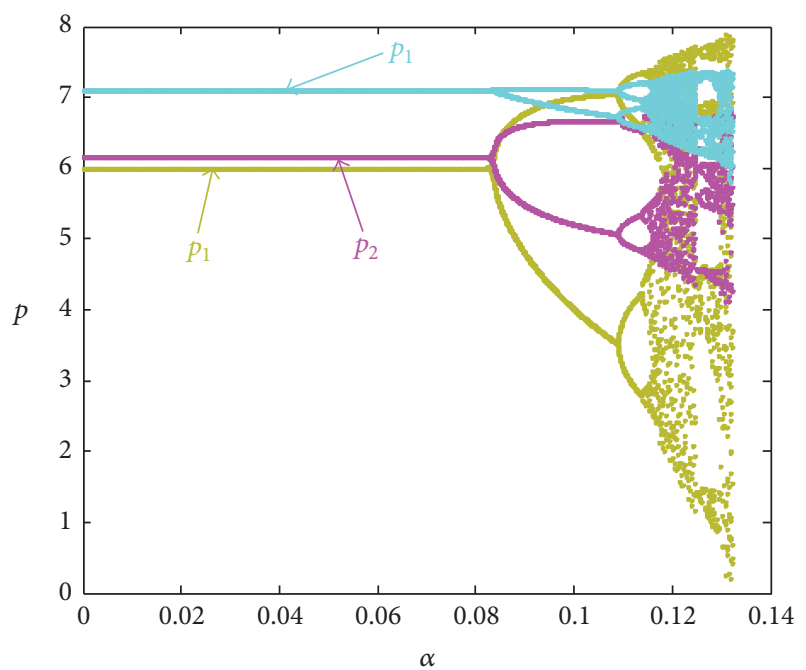

Figure 2: The bifurcation diagram of system (7) when $\beta=0.075$, $\gamma=0.08$, and $\alpha \in(0,0.14)$.

structured type. It means that the cooperation-competition relationship in CPs market is disordered and inefficient. If the triopoly system remains in chaotic state, the three firms have to change their pricing mechanism instead of bounded rational adjustment strategy. Since we assume that this is an incomplete information market, information asymmetry and the changed strategy will lead firms to a suboptimal choice to pursue maximum and steady profit.

Figure 5 is the bifurcation diagram of parameter $\beta$ for firm 2, when given values are $\alpha=0.075$ and $\gamma=0.08$. Combined with Figure 6 which is the largest Lyapunov exponent diagram, we obtain similar results of firm 1. For values of $\beta<0.08156$, the largest Lyapunov exponents are 




FIgURE 3: The largest Lyapunov exponent diagram of system (7) when $\beta=0.075, \gamma=0.08$, and $\alpha \in(0,0.14)$.



FIGURE 4: The chaotic attractor diagram of system (7) when $\beta=$ $0.075, \gamma=0.08$, and $\alpha=0.1233$.

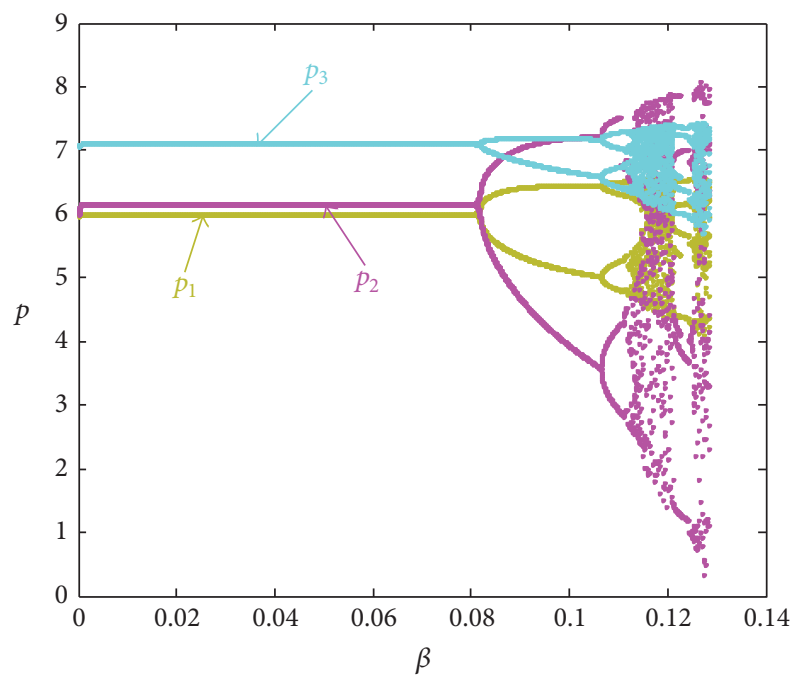

FIgURE 5: The bifurcation diagram of system (7) when $\alpha=0.075$, $\gamma=0.08$, and $\beta \in(0,0.14)$.



FIgURE 6: The largest Lyapunov exponent diagram of system (7) when $\alpha=0.075, \gamma=0.08$, and $\beta \in(0,0.14)$.

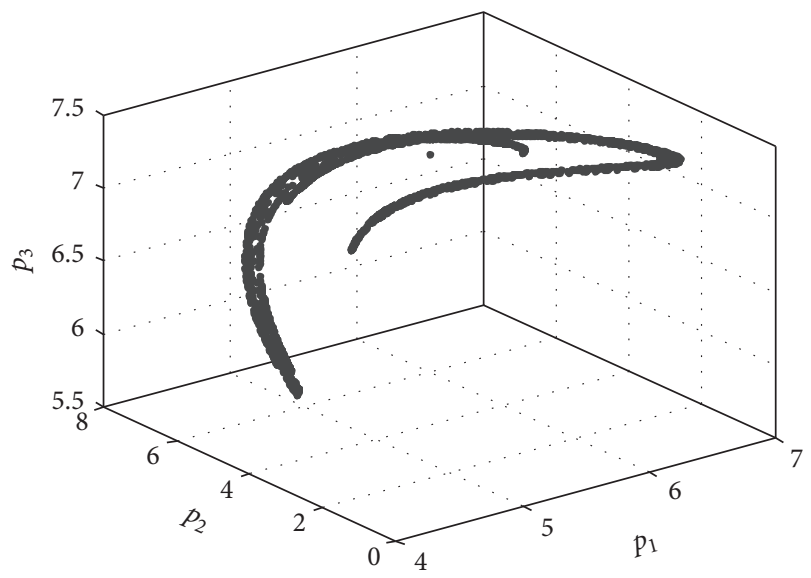

FIGURE 7: The chaotic attractor diagram of system (7) when $\alpha=$ $0.075, \gamma=0.08$, and $\beta=0.121$.

negative, so the Nash equilibrium is locally stable in this case. With increases of $\beta$, the Nash equilibrium turns to be unstable and the price decisions for the three firms are continually bifurcating from the equilibrium and eventually enter into chaos when $\beta>0.112$. The chaos attractor diagram in Figure 7 also illustrates the chaotic phenomenon for adjustment parameter of firm 2 when $\alpha=0.075, \gamma=0.08$, and $\beta=0.121$.

Figure 8 shows the bifurcation diagram of firm 3, which is the initial monopolist in CPs and keeps its product line unchanged to expect a rise in demand against the united R\&D activity of firm 1 and firm 2 . Combined with Figures 9 and 10, it is noted that the critical values of the adjustment speed, where the system passes through bifurcations to chaos, are distinctively larger than that of firms from BPs. The first bifurcating value for $\gamma$ is 0.117 and system (7) becomes chaotic when $\gamma=0.1761$.

For more analysis, it can be seen that the cooperation between firm 1 and firm 2 provides a complementary 


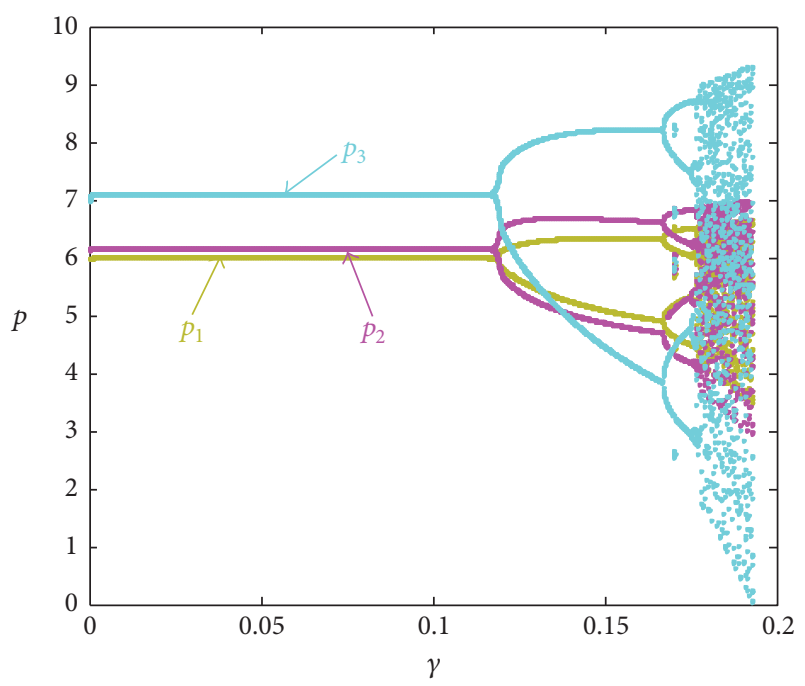

FIgURE 8: The bifurcation diagram of system (7) when $\alpha=\beta=0.075$ and $\gamma \in(0,0.20)$.

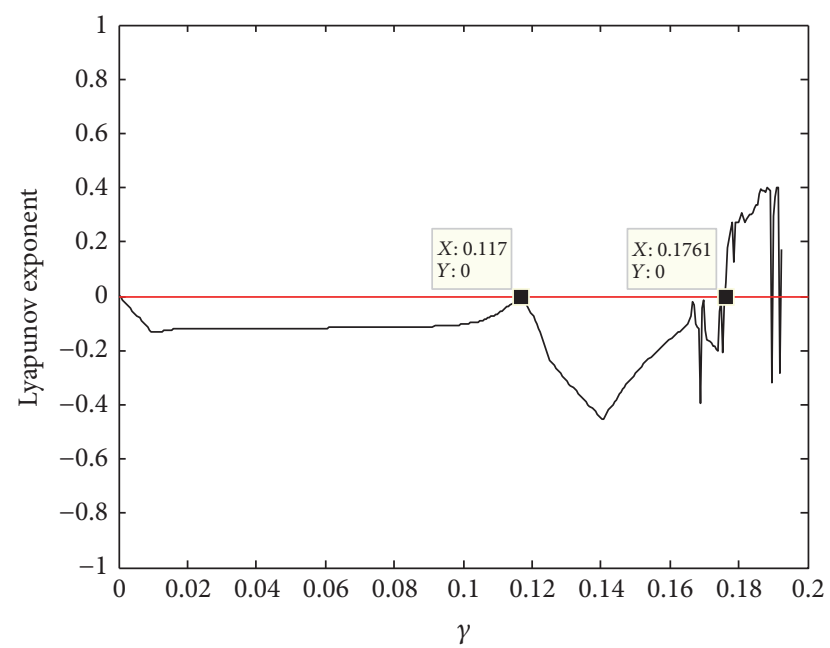

Figure 9: The largest Lyapunov exponent diagram of system (7) when $\alpha=\beta=0.075$ and $\gamma \in(0,0.20)$.

opportunity to compete with firm 3 in CPs market. But the players' adjustment speed from both sides of BPs can significantly influence stability of the CPs market. Besides, it proves that the market shows higher tolerance to the adjustment strategy of firm 3 which is an early monopolist in the market. An early entry can build up valuable advantages from aspects like the huge potential demands, the industryleading technologies and standards, good brand reputations, and so forth. Therefore, in a competitive CPs environment, it is also advisable for enterprises to take an opening strategic attitude to acquire the first-mover advantages.

\section{Chaos Control}

In CPs market, all the three players are expected to achieve maximum and steady profit. But the price adjustment strategy



FIgURE 10: The chaotic attractor diagram of system (7) when $\alpha=$ $\beta=0.075$ and $\gamma=0.179$.

should not be independent for the three firms. With increase of the adjustment parameters, the system generates bifurcations and eventually falls into chaos state, which means disorder and difficulty in making arrangement for enterprises in this field. In this section, we choose the parameter feedback method to control chaos in system (7), which is often used in other literatures to eliminate or delay chaos in general discrete systems.

The original triopoly cooperation-competition can be written as

$$
p_{i}(t+1)=f_{i}\left(p_{1}(t), p_{2}(t), p_{3}(t)\right) .
$$

We introduce the controlling parameter $\mu(\mu \in[0,1])$ into this system. Then the controlled system can be given as $p_{i}(t+$ $1)=(1-\mu) f_{i}\left(p_{1}(t), p_{2}(t), p_{3}(t)\right)+\mu p_{i}(t)$; that is,

$$
\begin{aligned}
& p_{1}(t+1)=(1-\mu)\left\{p_{1}(t)+\alpha p_{1}(t)\right. \\
& \quad \times\left[(1+\lambda)\left(a_{1}-b_{1} p_{1}(t)+c_{1} p_{2}(t)+d_{1} p_{3}(t)\right)\right. \\
& \left.\left.\quad-b_{1}(1+\lambda) p_{1}(t)-(e-r)\left(c_{2}-b_{1}\right) \theta+b_{1} g_{1}\right]\right\} \\
& \quad+\mu p_{1}(t), \\
& p_{2}(t+1)=(1-\mu)\left\{p_{2}(t)+\beta p_{2}(t)\right. \\
& \quad \times\left[(1+\lambda)\left(a_{2}-b_{2} p_{2}(t)+c_{2} p_{1}(t)+d_{2} p_{3}(t)\right)\right. \\
& \quad-b_{2}(1+\lambda) p_{2}(t)-(e-r)\left(c_{1}-b_{2}\right)(1-\theta) \\
& \left.\left.\quad+b_{2} g_{2}\right]\right\}+\mu p_{2}(t), \\
& p_{3}(t+1)=(1-\mu)\left\{p_{3}(t)+\gamma p_{3}(t)\left[a_{3}+b_{3} g_{3}+c_{3} p_{1}\right.\right. \\
& \left.\left.\quad+d_{3} p_{2}-2 b_{3} p_{3}\right]\right\}+\mu p_{3}(t) .
\end{aligned}
$$

When $\mu=0$, the controlled system degenerated to the original uncontrolled system. When $\mu=0$, system (13) becomes $p_{i}(t+1)=p_{i}(t)$. In this case, the players take simple price strategy as in last period but lose the opportunity to achieve more profits in the market. 


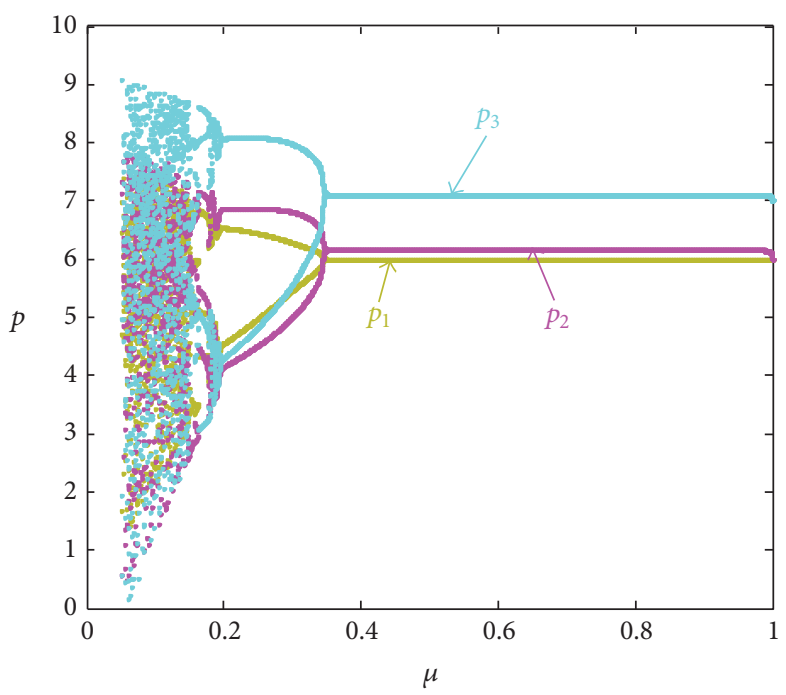

FIGURE 11: Chaos controlling performance with parameter $\mu$.
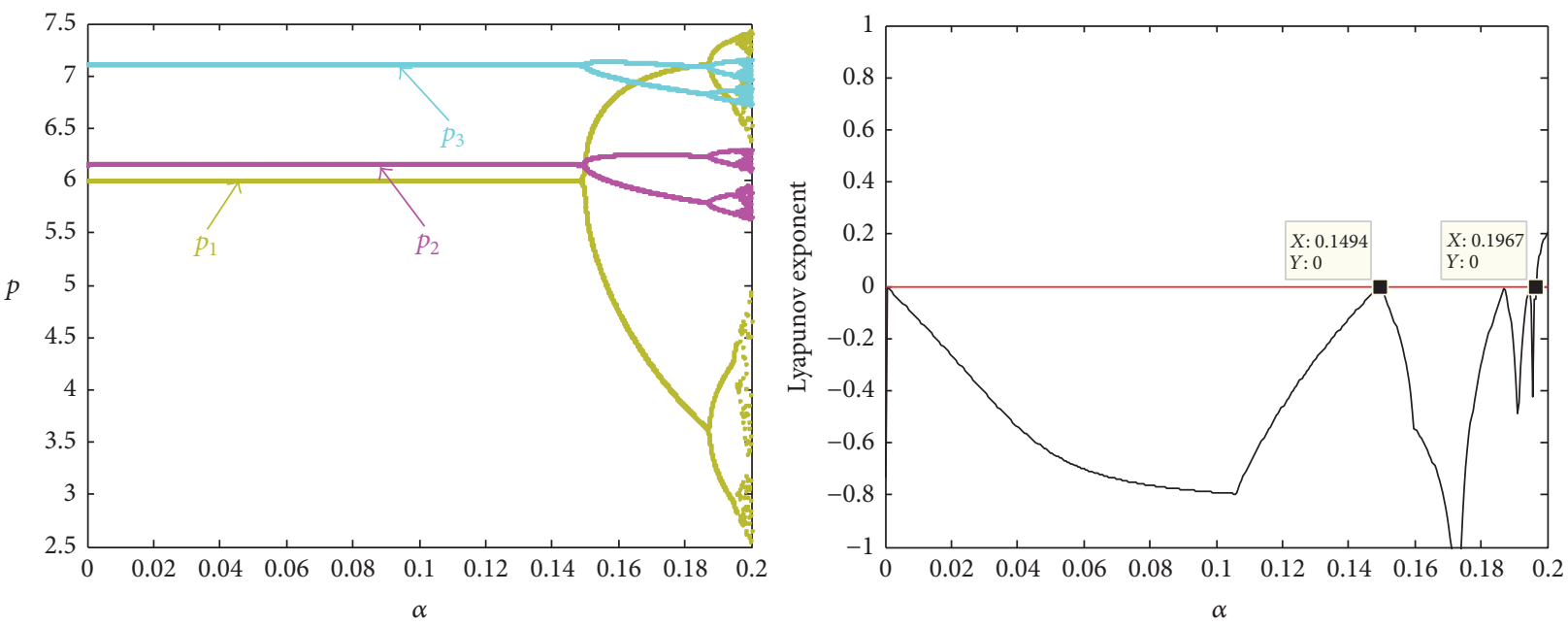

FIGURE 12: Performance of the controlled system on parameter $\alpha$.

Substituting (7) into (13), we use numerical simulations to illustrate the effect of $\mu$ on the stable region of the Nash equilibrium and the chaos controlling performance for system (7). Take $\alpha=\beta=0.115$ and $\gamma=0.18$ and other parameters are the same as in Section 3. In this case, system (7) is in chaos state and Figure 11 gives the bifurcation diagram of the three firms' price range regarding on controlling parameter $\mu$.

It can be seen from Figure 11 that the original system has been controlled from chaos to periodic bifurcations with the increase of $\mu$ and eventually recovered to stable state when $\mu>0.35$, which indicates that the chaotic system is effectively controlled with the controlling parameter. Take $\mu=0.4$, and the bifurcation diagrams and the largest Lyapunov exponent diagrams of the controlled system (13) with respect to $\alpha, \beta$, and $\gamma$ are given in Figures $12-14$. It shows that the controlled system (13) can be stabilized to the Nash equilibrium and chaos has been significantly eliminated or delayed for parameters in its feasible basin. Compared with the numerical simulation results in Section 3, the critical value of the price adjustment speed $\alpha$ where system (7) occurs as the first flip bifurcation has been increased from 0.8342 to 0.1494 , and the turning point where system (7) transforms from multiperiodic orbits to chaos has been delayed from 0.11151 to 0.1967 . The stability analysis of parameters $\beta$ and $\gamma$ also proved the controlling performance on chaotic system. In this case, the stable region of system (7) is enlarged for a wider range of $\alpha, \beta$, and $\gamma$, where the system converges to the Nash equilibrium.

In an associated economic system, a chaos state means disordered and inefficient competition in the market. The controlling performance of $\mu$ on the chaotic system shows that reasonable interventions or regulations on CPs are necessary and the learning ability or adaptability can be considered when making price decisions by analyzing the 

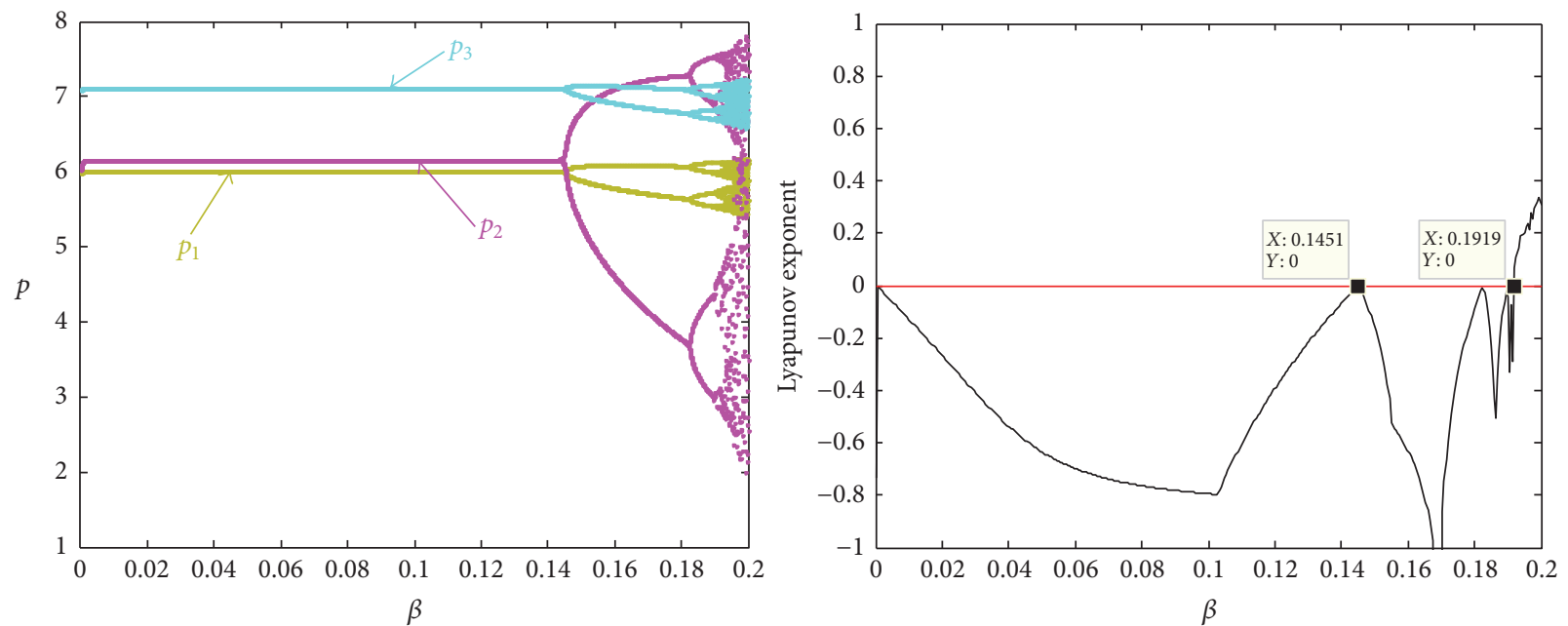

FIGURE 13: Performance of the controlled system on parameter $\beta$.
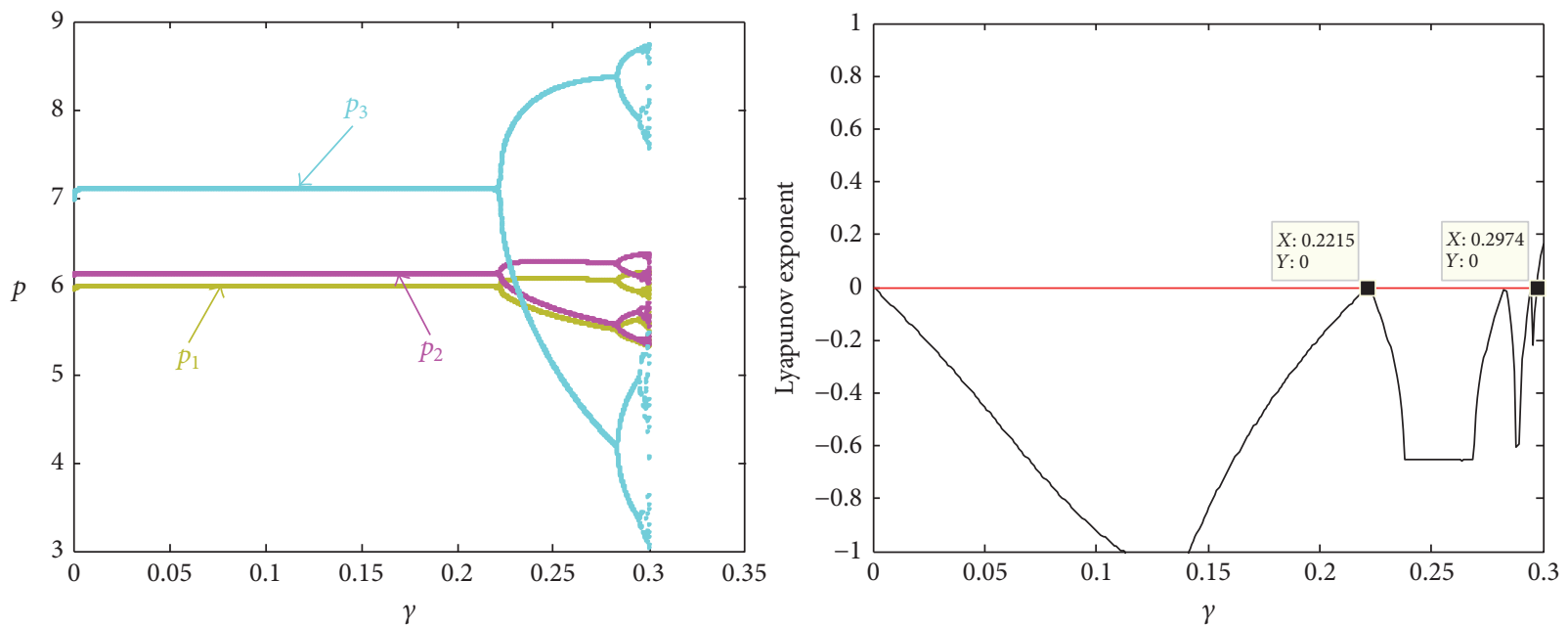

FIGURE 14: Performance of the controlled system on parameter $\gamma$.

past information for enterprises in this market. In addition, in an incomplete information market, the firms have limited information on output and pricing strategy of its competitors. So the three firms should be more cautious to make a decision. The price adjustment speed for each firm is not independently decided; it needs collaborative cooperation for all the three firms to pull the chaotic system back into stability.

\section{Conclusions}

In this paper, we investigate the complexity property of a triopoly game model in the convergence product market which contains three players: an early entry monopolist and two potential entrants from the base product market. Because of the nonindependent price decision mechanism and intentions to pursue the maximum profits, the cooperation and competition behaviors among the players will lead to complex dynamic results in this system. The costsharing competition for the two cooperative BPs firms and the alternative competition among the CPs and BPs firms will be eventually reflected in their price decision strategies. We find that the pulling effect on profit form R\&D activity can affect the stable range of the Nash equilibrium. So the first-mover strategy is recommended for enterprises who are preparing for entering a convergence product market. The system presents complex bifurcation and chaos behaviors if the adjustment speed exceeds a critical value. An effective parameter feedback control method can be applied to delay or eliminate the chaos state for the system, which supports the idea of reasonable interventions and regulation measures. Parameter values in real case scenarios rely on more empirical studies with variations of composition and structure analysis for specific convergence product. This study helps to better understand the fluctuations in general convergence product market and has theoretical and practical meaning when 
making price decision and strategy selection for enterprises in related fields.

\section{Competing Interests}

The authors declare that there is no conflict of interests regarding the publication of this paper.

\section{References}

[1] Z. Wang, C. Chen, B. Guo, Z. Yu, and X. Zhou, "Internet plus in China," IT Professional, vol. 18, no. 3, pp. 5-8, 2016.

[2] A. Fishman and R. Rafael, "Product innovation by a durablegood monopoly," The RAND Journal of Economics, vol. 31, no. 2, pp. 237-252, 2000.

[3] E. Danneels, "The dynamics of product innovation and firm competences," Strategic Management Journal, vol. 23, no. 12, pp. 1095-1121, 2002.

[4] T. Gill, "Convergent products: what functionalities add more value to the base?" Journal of Marketing, vol. 72, no. 2, pp. 46-62, 2008.

[5] E. M. Okada, "Upgrades and new purchases," Journal of Marketing, vol. 70, no. 4, pp. 92-102, 2006.

[6] H. N. Agiza and A. A. Elsadany, "Nonlinear dynamics in the Cournot duopoly game with heterogeneous players," Physica A. Statistical Mechanics and its Applications, vol. 320, no. 1-4, pp. 512-524, 2003.

[7] G. Symeonidis, "Comparing Cournot and Bertrand equilibria in a differentiated duopoly with product $\mathrm{R} \& \mathrm{D}$," International Journal of Industrial Organization, vol. 21, no. 1, pp. 39-55, 2003.

[8] H. Yang, M. Zhang, and M. Lai, "Complex dynamics of Cournot game with bounded rationality in an oligopolistic electricity market," Optimization and Engineering, vol. 12, no. 4, pp. 559582, 2011.

[9] F. Chen, J. H. Ma, and X. Q. Chen, "The study of dynamic process of the triopoly games in chinese $3 \mathrm{G}$ telecommunication market," Chaos, Solitons and Fractals, vol. 42, no. 3, pp. 15421551, 2009.

[10] C. H. Tremblay and V. J. Tremblay, "The Cournot-Bertrand model and the degree of product differentiation," Economics Letters, vol. 111, no. 3, pp. 233-235, 2011.

[11] S. S. Askar, A. M. Alshamrani, and K. Alnowibet, "The arising of cooperation in Cournot duopoly games," Applied Mathematics and Computation, vol. 273, pp. 535-542, 2016.

[12] A. A. Elsadany, "Competition analysis of a triopoly game with bounded rationality," Chaos, Solitons \& Fractals, vol. 45, no. 11, pp. 1343-1348, 2012.

[13] E. M. Elabbasy, H. N. Agiza, and A. A. Elsadany, "Analysis of nonlinear triopoly game with heterogeneous players," Computers and Mathematics with Applications, vol. 57, no. 3, pp. 488499, 2009.

[14] S. K. Ethiraj and D. Levinthal, "Bounded rationality and the search for organizational architecture: an evolutionary perspective on the design of organizations and their evolvability," Administrative Science Quarterly, vol. 49, no. 3, pp. 404-437, 2004.

[15] M. Pireddu, "Chaotic dynamics in three dimensions: a topological proof for a triopoly game model," Nonlinear Analysis. Real World Applications, vol. 25, pp. 79-95, 2015.

[16] D. A. Heiner, "Microsoft: a remedial success?" Antitrust Law Journal, vol. 78, no. 2, pp. 329-362, 2012.
[17] J. M. Pennings and P. Puranam, "Market convergence \& firm strategy: new directions for theory and research," in Proceedings of the ECIS Conference, The Future of Innovation Studies, Eindhoven, The Netherlands, 2001.

[18] M. Lee and Y. Cho, "Consumer perception of a new convergence product: a theoretical and empirical approach," Technological Forecasting and Social Change, vol. 92, pp. 312-321, 2015.

[19] S. Elaydi, An Introduction to Difference Equations, Springer, 2005.

[20] E. Beltrami, Mathematics for Dynamic Modeling, Academic Press, Boston, Mass, USA, 1987. 


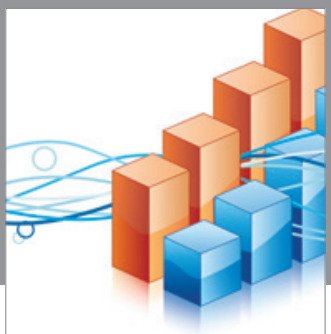

Advances in

Operations Research

vatem alat4



\section{The Scientific} World Journal
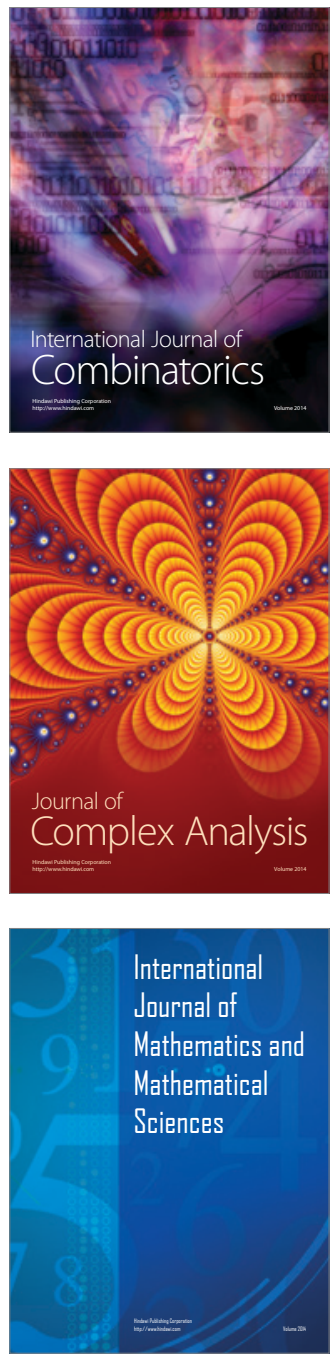
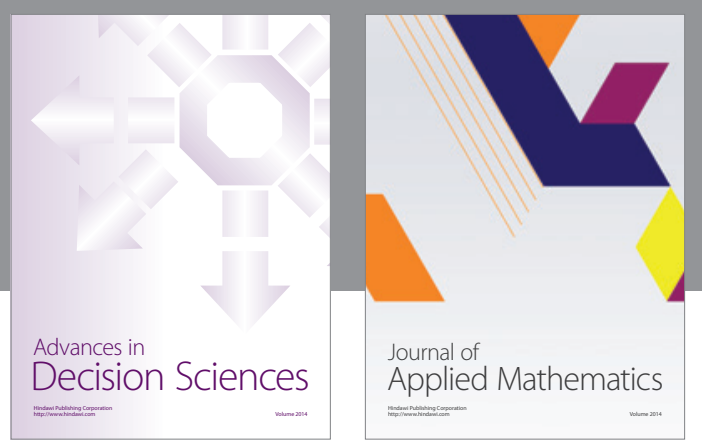

Algebra

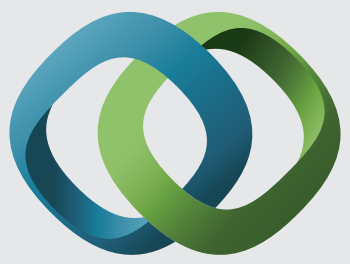

\section{Hindawi}

Submit your manuscripts at

https://www.hindawi.com


Mathematical Problems in Engineering
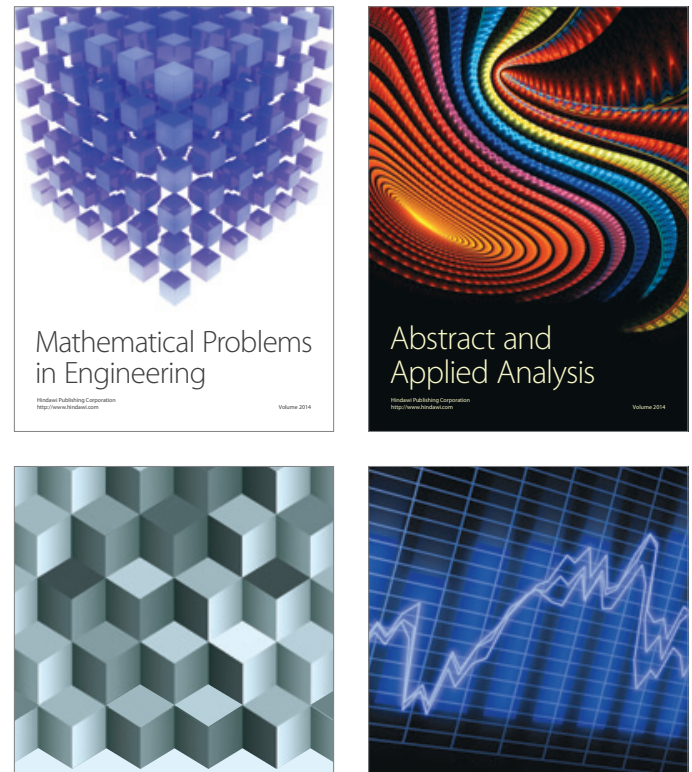

Journal of

Function Spaces

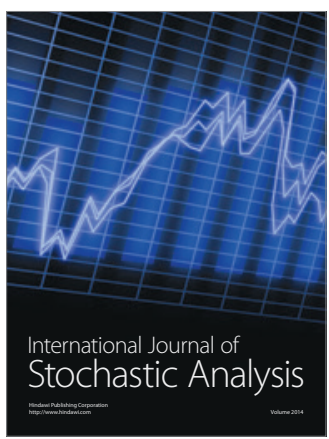

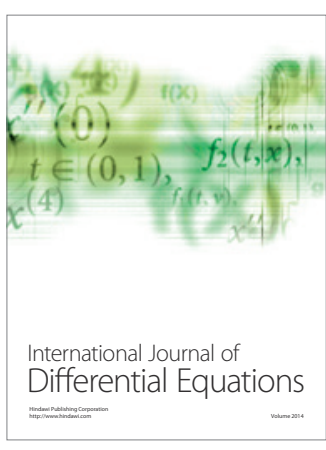
